\title{
The Perceptions of Senior High School Students and Teachers about Organic Chemistry: A Ghanaian Perspective
}

\author{
Esther Nartey*, Ruby Hanson \\ Department of Chemistry Education, University of Education, Winneba, Ghana
}

*Corresponding Author: narteyesther@ymail.com

\section{ABSTRACT}

The purpose of the study was to determine the perceptions that senior high school (SHS) chemistry students, and teachers have about organic chemistry as well as to compare organic chemistry topics that are difficult for students and teachers. Simple random sampling (lottery) and purposive sampling methods were used to select a sample of 100 SHS students who studied elective chemistry and ten chemistry teachers. The research instruments used to collect data for this study were the "organic chemistry perceptions questionnaire for students" and "organic chemistry perceptions questionnaire for teachers." Descriptive statistics (frequencies and percentages) were used to analyze the data collected. The findings revealed that these SHS students have a fairly positive perception of organic chemistry while their teachers had a highly positive perception of organic chemistry. Preparation and chemical reactions of alkenes, preparation and chemical reactions of alkynes, structure and stability of benzene, reactions of benzene, comparison of reactions of benzene and alkenes, petroleum, polymers and naming of alkanes, and structural isomerism were perceived by students as difficult to understand. The rest of the Ghanaian SHS organic chemistry topics (26 out of 34 topics) were perceived as easy to understand by students. Furthermore, the teachers perceived all the SHS organic chemistry topics as easy to teach with the exception of reactions of benzene. The insights gained about teachers' and students' perceived difficult organic chemistry topics in this study imply that teachers' perceptions and how these are communicated to students can have significant effects on learning. The authors believe that both teachers and learners could benefit from this increased awareness of perceptions about difficulties in teaching and learning organic chemistry. They therefore suggest that further studies into how teachers' perceptions influence their teaching and consequently their students' experiences are carried out. In addition, in future research, a diagnostic test based on the topics in the SHS organic chemistry syllabus could be added to ascertain whether the perceived difficult topics are actually difficult for students to answer questions on. This would help teachers to separate perceived difficulties from the actual difficulties (realities) and be able to address them in their lessons.

KEY WORDS: perceptions; difficulty; organic chemistry; students; teachers

\section{INTRODUCTION}

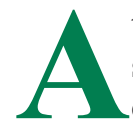

t a symposium organized by the American chemical society in 2016, many of the speakers who were educators agreed that organic chemistry has always been in crisis and that students have been saying that organic chemistry is difficult for a long time (Halford, 2016). A search through available literature has further revealed that a lot of researchers (Childs and Sheehan, 2009; Jimoh, 2004; Johnstone, 2006; Ratcliffe, 2002) have identified organic chemistry as one of the most difficult topics in chemistry. Topics such as petroleum, natural and synthetic polymers (Donkoh, 2017; Uchegbu et al., 2017), differentiating of functional groups (Ayalew and Ochonogor, 2015; O’Dwyer and Childs, 2017), benzene (Donkoh, 2017), drawing and representation of organic compounds (Johnstone, 2006; Taber, 2002), isomerism (Taagepera and Noori, 2000), properties of organic compounds (Anderson and Bodner, 2008), aromatic hydrocarbons (Davis, 2010), and classification of organic compounds (Domin et al., 2008; Hassan et al., 2004) have been listed as difficult for students and teachers by the various researchers.
(Hanson, 2014; 2016) also identified that the inability of Ghanaian students to understand the nature of matter and connect among the three representational levels of matter (macroscopic, microscopic, and representational) are the main factors that impede their study of chemistry. According to (Hanson, 2017), most students are unable to understand these representations well and thus form a faulty and weak foundation for further study of chemical concepts, especially in organic chemistry. Adu-Gyamfi et al. (2013) also carried out studies on students' conceptions and performance in international union of pure and applied chemistry (IUPAC) nomenclature of organic compounds and found that Ghanaian high school students had weak performance in naming and writing structural formulae of alkenes, alkynes, alkanols, alkanoic acids, and alkyl alkanoates. Further studies by (Adu-Gyamfi et al., 2017) showed that students' difficulties in IUPAC naming of organic compounds included their inability to identify the correct number of carbon atoms in the parent chain and to identify a substituent or functional group. Similar studies by (Davis, 2010) and (Donkoh, 2017) revealed that high school students perceived classification of organic compounds 
and petroleum as difficult to understand (DU) while their teachers did not perceive any of the Ghanaian high school organic chemistry topics as difficult to teach. To remediate these difficulties, (Hanson, 2016; 2017) suggested that teachers can use concrete examples to enable students to form mental models in order to alleviate the abstractness of chemical concepts and begin their lessons by asking questions related to everyday life events so that the context of the properties or answers could be steered to the classroom and its scientific or chemical aspect emphasized through individual, small group and whole class discussions.

However, despite the efforts by teachers to improve the performance of students in organic chemistry, the main body in charge of Ghanaian senior high school (SHS) examinations the West African Examinations Council (WAEC) consistently reports poor performance of students in organic chemistry. Recent WAEC chief examiners' reports on chemistry (West African Examinations Council, 2017; 2018) note that students showed the following weaknesses: inability to recall the terms such as catalytic cracking, functional groups, aliphatic compounds, aromatic compounds, inability to draw structures of organic compounds indicating all bonds, and drawing how the carbon-carbon double bonds in alkenes are formed. These suggest that students still have problems with learning organic chemistry.

In teaching organic chemistry, it is critical that educators are aware of the cognitive level and ability of their learners, if not the learners will be overwhelmed by the multi-level cognitive demands of chemistry as well as the other scientific and mathematical demands of the subject (O'Dwyer and Childs, 2017). This is because what might be easy for the teacher to understand might not be easy for the student to understand due to their differences in experiences and cognitive abilities. It is therefore important that teachers are made aware of their learners' attitudes, preconceptions, and perceptions. So that they will be able to tailor their instructions to ensure meaningful learning as students' attitudes and perceptions about a subject can in the long run influence their performance in that subject, hence the need for this study. In this study, the perceptions of students and teachers about organic chemistry as well as difficult topics in organic chemistry for students and teachers were evaluated and compared descriptively. This study sought to:

1. Evaluate selected SHS students' and teachers' perceptions about organic chemistry

2. Compare students' difficult organic chemistry topics to teachers' difficult organic chemistry topics.

Based on the specific objectives stated above, the following research questions were formulated to guide this study.

1. What are the SHS students' and teachers' perceptions of organic chemistry?

2. Which are the differences and similarities in organic chemistry topics that students and teachers perceive to be difficult?

\section{DESIGN AND PROCEDURES}

The study, which used a descriptive survey design, involved a $1003^{\text {rd }}$-year SHS 3 general science students and 10 elective chemistry teachers from three selected schools in the central region of Ghana. The student participants, with ages from 15 to 24 years, were selected through simple random sampling while the teacher participants were selected through purposive sampling. The student and teacher participants in the three selected schools had either been taught or taught organic chemistry.

Ethical standards were upheld during the research as the principles of confidentiality, anonymity and informed consent were applied. Before carrying out the research, the researchers sought permission from the administrators of the concerned schools. The researchers explained the purpose of the study and the methods to be used to carry out the study to school administrators and participants (both student and teacher participants). Participants were then given the option of opting out if they did not want to be part of the study. The student and teacher participants who were used for this study voluntarily accepted to take part in the study. The identity of the schools, respondents' identities and private information given during the study were kept private and confidential.

The "organic chemistry perception questionnaire for students" (OCPQS) and "organic chemistry perception questionnaire for teachers" (OCPQT) which were both adapted from (Davis, 2010) as well as (Ayalew and Ochonogor, 2015) were used in this study to secure information from the SHS 3 students and teachers on their perceptions of organic chemistry. The OCPQS (Appendix A) and OCPQT (Appendix B) were based on the Ghanaian Ministry of Education SHS elective chemistry syllabus and included both closed ended and open-ended questions. Both the OCPQS and OCPQT had three sections. The first section in the OCPQS collected respondents' biographic data. The second section which consisted of seven items focused on the students' perception of organic chemistry in general. The third section which consisted of 35 items sought to collect data on students' perception of organic chemistry topics. The items numbered one to 34 in the third section covered all the topics under organic chemistry in the SHS elective chemistry syllabus. To respond to the items, the respondents were required to indicate their perception of understanding of each of the listed topics on a six-point Likert scale: very easy to understand (EU), EU, understood only after considerable effort, DU, very DU, and not taught (NT). Item 35 solicited free responses on topics that students find most DU.

The OCPQT which was similar to the OCPQS included both closed- and open-ended items. The teachers' instrument was also made up of three sections; the first section sought information on teachers' biographic data as well as their educational background and teaching experience. The second section consisting of five items sought to find out teachers' perception of organic chemistry in general on a five-point Likert scale: strongly disagree, disagree, undecided, agree, and 
strongly agree. The third section consisting of 34 items sought information on teachers' perception of the topics in organic chemistry. To respond to items one to 34 , the respondents were required to indicate their perceptions of each of the listed topics on a similar five-point Likert scale which ranged from very easy to teach, easy to teach, not sure, difficult to teach and very difficult to teach.

To ensure the validity of the instruments, expert judgment of senior members in the field of science education was sought on the content and face validities of the instruments. The comments and suggestions from the experts were used in restructuring the items. Furthermore, factors that contribute to low validity such as unclear directions, and ambiguities in language were eliminated. The questionnaires were also tested in a pilot study using a sample of thirty randomly selected SHS 3 students and five teachers from a school with similar student and teacher characteristics. The pilot study was done specifically to help in checking the clarity of the items, give feedback on internal validity of the items and to ensure appropriateness of the data.

To ensure reliability, the data from the pilot study were used to test the internal consistency of the questionnaire.

\section{ANALYSIS OF DATA}

The research questions were used to guide the analysis of the data, that is, the data were analyzed to answer the research questions. The five-point Likert scales in section B of both the OCPQS and OCPQT were collapsed into 3-point scales for easy data entry and analysis. The scales "strongly agree" and "agree" were grouped as "agree" and assigned a number code of 3, "disagree" and "strongly disagree" were grouped as "disagree" and assigned a code of 1 while the "undecided" slot was also assigned a number code of 2 .

For the section C of students' questionnaire, the six-point Likert scale was collapsed to 4 with "very EU" and "EU" grouped as "EU" and assigned a number code of 4, "DU" and very "DU" grouped as "DU" and coded 2, and understood after considerable effort (UCE) was assigned a code of 3, "NT" was also coded as 1 . The collapsing of the six-point Likert scale to 4 was done to facilitate easy analysis of the data. The five-point Likert scale for section C of the OCPQT was also collapsed to 3 to make the data analysis easier. The scales "very easy to teach" and "easy to teach" were grouped as "easy to teach" which was assigned a number code of 3 , not sure was assigned a number code of 2 , while "difficult to teach" and very "difficult to teach" were grouped as "difficult to teach" and assigned a number code of 1 . The assignment of number codes to scales was done to facilitate easy entry of data into the Statistical Package for the Social Sciences (SPSS) computer software version 20 for analysis.

The coded data were statistically analyzed using the SPSS computer software version 20. Data were processed into frequencies and percentages. This was done to ensure clear description of gender, perception of students, and perception of teachers. Tables of frequencies and percentages obtained with the aid of SPSS were used to answer the research questions descriptively.

\section{RESULTS AND DISCUSSION}

\section{Students' General Perceptions about Organic Chemistry}

Presented in Table 1 is a summary of students' responses to statements in the OCPQS which sought information on students' general perceptions of organic chemistry as a subject. Students were asked to indicate their level of agreement or disagreement to statements to seek their general attitudes and perceptions of organic chemistry.

From Table 1, it can be seen that a considerable number of students (45) representing $45.0 \%$ of the student sample agreed that organic chemistry was a difficult subject for them while 48 students (48.0\%) disagreed. Although a simple majority disagreed that organic chemistry was difficult, the difference between the number of students who agreed and those who disagreed was not large, so it could be inferred that almost half of the student sample saw organic chemistry as difficult while the other half saw it as not difficult. This is in contrast to findings from a study on Irish high school learners and teachers' perceptions and perspectives of organic chemistry by (O'Dwyer and Childs, 2017) which revealed that less than one third $(75,27.5 \%)$ of the high school learners they studied found organic chemistry easy while 165 (59.8\%) of the learners found organic chemistry difficult to learn. In the current study, about $51 \%$ of the students agreed that organic chemistry concepts were very EU, 54\% found it easy to solve organic chemistry

\begin{tabular}{|c|c|c|c|c|}
\hline S. No. & Statement & $\%$ Agree & $\%$ Undecided & $\%$ Disagree \\
\hline 1 & Organic chemistry is a difficult topic for me & 45.0 & 7.0 & 48.0 \\
\hline 2 & It is easy to solve organic chemistry problems & 54.0 & 10.0 & 36.0 \\
\hline 3 & I am very happy during organic chemistry lessons & 63.6 & 7.1 & 29.3 \\
\hline 4 & Organic chemistry concepts are very EU & 51.0 & 7.0 & 42.0 \\
\hline 5 & $\begin{array}{l}\text { My chemistry teacher's method of teaching helped me to } \\
\text { understand organic chemistry concepts well }\end{array}$ & 58.60 & 15.10 & 26.30 \\
\hline 6 & Organic chemistry is interesting & 64.00 & 10.00 & 26.00 \\
\hline 7 & $\begin{array}{l}\text { I enjoy learning organic chemistry more than the other } \\
\text { aspects of chemistry }\end{array}$ & 29.30 & 11.10 & 59.60 \\
\hline
\end{tabular}

Source: Field data, 2019, EU: Easy to understand 
problems, $63 \%$ were happy during organic chemistry lessons, $58 \%$ agreed that their chemistry teacher's method of teaching helped them to understand organic chemistry concepts well, while $64 \%$ found organic chemistry interesting. However, $59 \%$ disagreed with the statement "I enjoy learning organic chemistry more than the other aspects of elective chemistry" while only $29 \%$ agreed to it. It could be inferred that if given the choice, the majority (59\%) of these students would choose to read the other aspects of chemistry over organic chemistry. In general, it could be said that students have a fairly positive perception of organic chemistry and a positive attitude toward it but would not choose to study organic chemistry over the other aspects of chemistry if given the chance.

\section{Teachers' General Perceptions about Organic Chemistry}

Table 2 presents a summary of teachers' responses to statements in the OCPQT which sought information on teachers' general perceptions of organic chemistry as a subject. Teachers were asked to indicate their level of agreement to statements.

It can be seen from Table 2 that all the teachers $(100 \%)$ disagreed with the statement "organic chemistry is a difficult subject for me," meaning that all the teachers viewed organic chemistry as an easy subject. Eight of the teachers (representing $80 \%$ ) agreed that organic chemistry concepts are very EU while two of them $(20 \%)$ disagreed with this statement. Six teachers agreed that it was easy to solve organic chemistry problems, three disagreed, and one teacher did not respond to the statement. Seven of the teachers enjoyed teaching organic chemistry topics more than the other aspects of chemistry while two of them did not enjoy teaching organic chemistry more than the other aspects of chemistry. When the teachers' response to this particular statement was compared with that of the students, there seems to be a mismatch between the enthusiasm of teachers about organic chemistry and that of their students. This mismatch could be attributed to the fact that teachers are "experts" while learners are just beginners in organic chemistry.

Furthermore, 7 teachers disagreed to the statement "organic chemistry topics are not interesting" while 1 agreed. Unlike the students who perceived organic chemistry as interesting but would choose the other aspects of chemistry over organic chemistry, the teachers perceived organic chemistry as easy and interesting and would choose to teach organic chemistry over the other aspects of chemistry.

\section{Students' Difficult Organic Chemistry Topics}

The summary of responses of students to the levels of difficulty posed by listed Ghanaian SHS organic chemistry topics are presented in Table 3. Students were asked to indicate the levels of difficulty of the listed organic chemistry topics. Abbreviations in the Table would be interpreted as: EU, Understood after considerable effort (UCE), DU, and NT.

From the summary of responses presented in Table 3, 29 out of the 34 listed topics were viewed by majority of students as EU. The topics which were perceived as DU by students were preparation and chemical reactions of alkenes, preparation and chemical reactions of alkynes, structure and stability of benzene, reactions of benzene, comparison of reactions of benzene and alkenes.

Preparation and chemical reactions of alkenes were chosen by $37 \%$ of students as difficult, and the same percentage of students (37\%) also choose it as EU. However, $24 \%$ of students asserted that they understood it only after considerable effort. If a concept must be UCE, then that understanding of that concept poses some level of difficulty and could be said to be fairly difficult. In view of this, it could be concluded that preparation and chemical reactions of alkenes was perceived as difficult by the SHS students. Different reasons could be attributed to the difficulties students face in studying. However, this was not part of the current study. The identified difficulty could be as a result of teacher factors (teachers' methodologies, punctuality and attendance to class, mastery of content and ability to deliver effectively), students' factor (students' attitude to learning, motivation, attendance to class, paying attention in class), and lack of teaching and learning materials or other extrinsic difficulty; difficulty associated with the subject itself beyond the control of the learner (O'Dwyer and Childs, 2017).

Comparison of the reactions of benzene and alkenes also had the same percentage (29\%) of students choosing "EU" and "DU" respectively while a greater percentage (32\%) understood it only after considerable effort. As stated earlier, the fact that considerable effort had to be put in before students understood concepts could mean that some level of difficulty had to be overcome, and therefore, the topic "comparison of the reactions of benzene and alkenes" could be said to be perceived as DU by SHS students.

A slightly higher percentage of students viewed the topics "preparation and chemical reactions of alkynes", "structure

\begin{tabular}{|c|c|c|c|c|}
\hline S. No. & Statement & Agree (\%) & Undecided (\%) & Disagree (\%) \\
\hline 1 & Organic chemistry is a difficult topic for me to teach & 0.0 & 0.0 & 100.0 \\
\hline 2 & Organic chemistry concepts are very EU & 80.0 & 0.0 & 20.0 \\
\hline 3 & It is easy to solve organic chemistry problems & 66.7 & 0.0 & 33.3 \\
\hline 4 & $\begin{array}{l}\text { I enjoy teaching organic chemistry more than other aspects } \\
\text { of chemistry }\end{array}$ & 70.0 & 10.0 & 20.0 \\
\hline 5 & Organic chemistry topics are not interesting & 10.0 & 20.0 & 70.0 \\
\hline
\end{tabular}

Source: Field data, 2019, EU: Easy to understand 
and stability of benzene" and "reactions of benzene" as EU (30\%, 35\%, and 33\%, respectively) as compared to those that viewed them as DU $(29 \%, 33 \%$, and $30 \%$, respectively). However, an equally appreciable percentage of students (36\%, $26 \%$, and $28 \%$, respectively) also viewed these topics as "understood only after considerable effort." If a topic is understood only after considerable effort, then it is DU (Davis, 2010). Conclusions could therefore be drawn that these topics were perceived to be difficult by the SHS students.

In addition, the topic on petroleum was viewed by $23 \%$ of students to be DU. About $22 \%$ of students saw it as EU while $23 \%$ saw it as a topic that could be understood only after considerable effort. This topic also recorded the highest percentage of students (27\%) responding to it as "NT." Students' difficulties in understanding "petroleum" could therefore be attributed to the probability that it was NT or the other reasons like teacher factors and student factors which have been stated earlier. Seeing that almost the same percentage of students that find petroleum DU also chose "NT," it could be that indeed most teachers did not teach petroleum due to the fact that petroleum is the last topic under organic chemistry in the SHS chemistry syllabus. It being the last topic could imply that teachers may not get to the topic because of time constraints. Another interpretation of the gathered data or assumption could be that the students were not present in class when "petroleum" was taught, or it was taught during extra classes where some of the students missed out. Polymers and polymerization also had quite a large percentage of students (25\%) perceiving it as DU and the second highest percentage of students saying it was NT (24\%).

Furthermore, students were required to list three most difficult topics in organic chemistry in item 35 of the OCPQS. From the responses students provided, the top five most difficult topics for students and their percentages were polymers and polymerization $(69 \%)$, structure and stability of benzene $(65 \%)$, reactions of benzene $(60 \%)$, naming of alkanes and structural isomerism (56\%), and petroleum (54\%). Comparing the difficult topics stated in Table 3 and those listed above, it could be seen that structure and stability of benzene, reactions of benzene, and petroleum appear in both lists, and therefore, it could be said that they are the top three topics perceived to be most DU by the students. Although polymers and polymerization and naming of alkanes and structural isomerism were not chosen by majority of students as DU in Table 3, they were stated by a large number of students as difficult. In similar research works (Ayalew and Ochonogor, 2015; Davis, 2010; O'Dwyer and Childs, 2017; Uchegbu et al., 2017), petroleum, benzene and synthetic polymers were also identified as topics that were perceived as difficult for students to understand.

Table 3: Students' level of difficulty in understanding organic chemistry topics

\begin{tabular}{|c|c|c|c|c|}
\hline Topics & EU (\%) & UCE (\%) & DU (\%) & NT (\%) \\
\hline Bonding in carbon & 73.0 & 14.0 & 12.0 & 1.0 \\
\hline Classification of organic compounds & 67.0 & 17.0 & 16.0 & 0.0 \\
\hline Identification of elements in organic compounds & 56.0 & 24.0 & 20.0 & 0.0 \\
\hline Separation and purification of organic compounds. & 54.0 & 21.0 & 23.0 & 2.0 \\
\hline Sources and characteristics of alkanes & 58.0 & 18.0 & 23.0 & 1.0 \\
\hline Naming of alkanes and structural isomerism & 65.0 & 18.0 & 17.0 & 0.0 \\
\hline Preparation, physical and chemical properties of alkanes & 53.0 & 21.0 & 24.0 & 2.0 \\
\hline Sources and characteristics of alkenes & 57.0 & 22.0 & 17.0 & 4.0 \\
\hline Naming of alkenes and isomerism in alkenes & 55.0 & 18.0 & 24.0 & 3.0 \\
\hline Preparation and chemical reactions of alkenes & 37.0 & 24.0 & 37.0 & 2.0 \\
\hline Uses of alkenes & 59.0 & 19.0 & 12.0 & 10.0 \\
\hline Sources and characteristic properties of alkynes & 48.0 & 28.0 & 22.0 & 2.0 \\
\hline Naming of alkynes and isomerism in alkynes & 49.0 & 24.0 & 25.0 & 2.0 \\
\hline Preparation and chemical reactions of alkynes & 30.0 & 36.0 & 29.0 & 5.0 \\
\hline Uses of alkynes & 61.0 & 20.0 & 15.0 & 4.0 \\
\hline The structure and stability of benzene & 35.0 & 26.0 & 33.0 & 6.0 \\
\hline Reactions of benzene & 33.0 & 28.0 & 30.0 & 9.0 \\
\hline Comparison of reactions of benzene and alkenes & 29.0 & 32.0 & 29.0 & 10.0 \\
\hline Preparation and properties of alkanols & 48.0 & 28.0 & 18.0 & 6.0 \\
\hline Physical properties of alkanols & 57.0 & 26.0 & 14.0 & 3.0 \\
\hline Primary, Secondary and tertiary alkanols & 59.0 & 18.0 & 20.0 & 3.0 \\
\hline Chemical reactions of alkanols & 46.0 & 24.0 & 25.0 & 5.0 \\
\hline Sources, preparation and properties of alkyl alkanoates & 38.0 & 25.0 & 30.0 & 7.0 \\
\hline Naming and structure of alkyl alkanoates & 48.0 & 19.0 & 29.0 & 4.0 \\
\hline Uses of alkyl alkanoates & 42.0 & 23.0 & 29.0 & 6.0 \\
\hline Soapy and soapless detergents & 39.0 & 23.0 & 21.0 & 17.0 \\
\hline Polymers and polymerization & 33.0 & 18.0 & 25.0 & 24.0 \\
\hline Petroleum & 22.0 & 28.0 & 23.0 & 27.0 \\
\hline
\end{tabular}

Source: Field data, 2019, EU: Easy to understand, UCE: Understood after considerable effort, DU: Difficult to understand, NT: Not taught 


\section{Teachers' Difficult Organic Chemistry Topics}

Table 4 provides a summary of responses of teachers to the levels of difficulty posed by listed Ghanaian SHS organic chemistry topics. Teachers were asked to indicate the levels of difficulty of the listed organic chemistry topics.

Comparatively, it can be seen from Table 4 that these teachers generally perceived all organic chemistry topics as easy to teach with the exception of reactions of benzene. This agrees with findings from (Donkoh, 2017) who also stated that chemistry teachers perceived none of the SHS organic chemistry topics as difficult to teach. It is however important to note that the fact that teachers rate a topic as easy to teach does not mean it is best taught (taught well) neither does a teacher rating a topic as difficult to teach make that topic the most poorly taught topic (not well taught) as these results are only representative of the teachers' views (O'Dwyer and
Childs, 2017). This means that a topic could be rated as easiest to teach by teachers but may end up not being well taught and a topic rated most difficult to teach might end up being well taught by a teacher. Teachers may be able to teach these topics to the understanding of their students or not.

The few topics which recorded an appreciable number of teachers viewing them as difficult to teach are identified below. The following topics were perceived as difficult to teach by at least $40 \%$ of the teachers: preparation and chemical reactions of alkynes (40\%), the structure and stability of benzene (40\%), reactions of benzene $(50 \%)$, comparison of reactions of benzene and alkenes (40\%), and polymers and polymerization (40\%). A lot of factors could contribute to a teacher's difficulty in teaching a particular topic. Some of the factors may be the extensive nature of the content (loaded content), high cognitive demand of the content, lack of teaching and learning materials

\section{Table 4: Teachers' perceptions about difficulty levels of organic chemistry topics}

\begin{tabular}{|c|c|c|c|}
\hline Topics & Easy to teach (\%) & Not sure (\%) & Difficult to teach (\%) \\
\hline 1. Bonding in carbon & 100.0 & 0.0 & 0.0 \\
\hline 2. Classification of organic compounds & 90.0 & 10.0 & 0.0 \\
\hline 3. Identification of elements in organic compounds & 90.0 & 0.0 & 10.0 \\
\hline $\begin{array}{l}\text { 4. Separation and purification of organic compounds, } \\
\text { empirical and molecular formulae }\end{array}$ & 90.0 & 10.0 & 0.0 \\
\hline 5. Sources and characteristics of alkanes & 100.0 & 0.0 & 0.0 \\
\hline 6. Naming of alkanes and structural isomerism & 90.0 & 10.0 & 0.0 \\
\hline 7. Preparation and properties of alkanes & 70.0 & 0.0 & 30.0 \\
\hline 8. Uses of alkanes & 90.0 & 0.0 & 10.0 \\
\hline 9. Sources and characteristics of alkenes & 80.0 & 0.0 & 20.0 \\
\hline 10. Naming of alkenes and isomerism in alkenes & 90.0 & 0.0 & 10.0 \\
\hline 11. Preparation and chemical reactions of alkenes & 70.0 & 0.0 & 30.0 \\
\hline 12. Uses of alkenes & 90.0 & 0.0 & 10.0 \\
\hline 13. Sources and characteristic properties of alkynes & 80.0 & 10.0 & 10.0 \\
\hline 14. Naming of alkynes and isomerism & 90.0 & 0.0 & 10.0 \\
\hline 15. Preparation and chemical reactions of alkynes & 60.0 & 0.0 & 40.0 \\
\hline 16. Uses of alkynes & 80.0 & 10.0 & 10.0 \\
\hline 17. The structure and stability of benzene & 60.0 & 0.0 & 40.0 \\
\hline 18. Reactions of benzene & 50.0 & 0.0 & 50.0 \\
\hline 19. Comparison of reactions of benzene and alkenes & 60.0 & 0.0 & 40.0 \\
\hline 20. Preparation and properties of alkanols & 100.0 & 0.0 & 0.0 \\
\hline 21. Physical properties of alkanols & 100.0 & 0.0 & 0.0 \\
\hline 22. Naming of alkanols & 90.0 & 10.0 & 0.0 \\
\hline 23. Primary, Secondary and tertiary alkanols & 90.0 & 0.0 & 10.0 \\
\hline 24. Chemical reactions of alkanols & 80.0 & 0.0 & 20.0 \\
\hline 25. Uses of alkanols & 100.0 & 0.0 & 0.0 \\
\hline 26. Sources and properties of alkanoic acids & 90.0 & 0.0 & 10.0 \\
\hline 27. Naming of alkanoic acids & 100.0 & 0.0 & 0.0 \\
\hline 28. Uses of alkanoic acids & 100.0 & 0.0 & 0.0 \\
\hline 29. Sources and properties of alkyl alkanoates & 80.0 & 10.0 & 10.0 \\
\hline 30. Naming and structure of alkyl alkanoates & 90.0 & 0.0 & 10.0 \\
\hline 31. Uses of alkyl alkanoates & 90.0 & 0.0 & 10.0 \\
\hline 32. Soapy and soapless detergents & 80.0 & 0.0 & 20.0 \\
\hline 33. Polymers and polymerization & 50.0 & 10.0 & 40.0 \\
\hline 34. Petroleum & 70.0 & 0.0 & 30.0 \\
\hline
\end{tabular}

Source: Field data, 2019 
such as textbooks, laboratory equipment, and lack of mastery over the content by the teacher (Mupa and Chinooneka, 2015).

\section{Comparison of Students' Difficult Topics in Organic} Chemistry to Teachers' Difficult Organic Chemistry Topics Teaching and learning is a complex process with many internal and external factors influencing classroom experiences and relationships. The teachers' perspectives, and how the material is presented, have considerable impact on the learners' experiences and development of understanding. That is the reason why the authors saw the need to compare students' difficult topics to their teachers' difficult topics.

An appreciable number of teachers perceived the topics preparation and chemical reactions of alkynes (40\%), the structure and stability of benzene (40\%), reactions of benzene $(50 \%)$, comparison of reactions of benzene and alkenes $(40 \%)$, and polymers and polymerization (40\%) as difficult to teach. On the other hand, the organic chemistry topics which were perceived to be DU by most students were: preparation and chemical reactions of alkenes, preparation and chemical reactions of alkynes, structure and stability of benzene, reactions of benzene, comparison of reactions of benzene and alkenes, polymers, and polymerization, naming of alkanes and structural isomerism and petroleum.

All the topics that teachers perceived to be difficult to teach were also perceived to be DU by their students. (O'Dwyer and Childs, 2017) explained that while teachers' positive attitudes, interest and enjoyment of organic chemistry may stimulate learners' respective experiences, teachers' perspectives and perceptions of many topics may on the other hand have substantial impact on their learners' perspectives and learning of many of the topics. The insights gained about teachers' and students' perceived difficult organic chemistry topics in this study imply that teachers' perceptions and how these are communicated with the students can have significant effects on learning. It is therefore important that teachers are aware of their influence on their learners in generating preconceptions about difficult topics. Although teachers are required to empathize with students by reassuring them, some findings have suggested that teachers' own perceptions of the difficulty of topics may influence the effectiveness of the teaching and learning of these topics and in turn influence their students' experiences and perceptions (O'Dwyer and Childs, 2017).

\section{CONCLUSIONS}

This study aimed at finding the differential perceptions of selected SHS teachers and students. The study specifically considered the general perceptions of students and teachers in selected SHSs in Ghana about organic chemistry. It perused the topics that students and teachers considered easy or DU and teach (for teachers). Findings revealed that the SHS teachers had a positive perception of organic chemistry and found 33 out of the 34 organic chemistry topics in the SHS chemistry syllabus easy to teach. Reactions of benzene of benzene was the only topic that $50 \%$ of the teachers found easy to teach while the other $50 \%$ found it difficult to teach. The students on the other hand also had a positive perception toward organic chemistry but would be interested in studying the other aspects of chemistry rather than organic chemistry. Students found 26 out of the 34 organic chemistry topics as EU. The topics that the students perceived to be DU were preparation and chemical reactions of alkenes, preparation and chemical reactions of alkynes, structure and stability of benzene, reactions of benzene, comparison of reactions of benzene and alkenes, petroleum, polymers and naming of alkanes and structural isomerism). Based on the findings from this study, organic chemistry teachers should pay extra attention (invest more time, varied teaching methodologies) when teaching the topics that have been identified by students in this study as DU. These authors believe will go a long way to help ease the difficulties that students encounter in studying these topics.

The teachers considered some topics as difficult to teach as they realized that those are the topics that their students had difficulty understanding. The same topics which were identified by teachers as difficult to teach were negatively perceived and poorly understood by majority of their students. This suggests that if better teaching strategies or approaches are made available and are used by the teachers, these topics may become easier to teach, and in turn easier for the learners to understand if they are better taught.

\section{IMPLICATIONS FOR CHEMISTRY EDUCATION}

The insights gained about teachers' and students' perceived difficult organic chemistry topics in this study imply that teachers' perceptions and how these are communicated to students can have significant effects on learning. It is therefore important that teachers are aware of their influence on their learners in generating preconceptions about difficult topics. Although teachers are required to empathize with students by reassuring them, some findings have suggested that teachers' own perceptions of the difficulty of topics may influence the effectiveness of the teaching and learning of these topics and in turn influence their students' experiences and perceptions (O'Dwyer and Childs, 2017). The authors believe that both teachers and learners could benefit from this increased awareness of perceptions about difficulties in teaching and learning chemistry. They therefore suggest that further studies into how teachers' perceptions influence their teaching and consequently their students' experiences are carried out.

In addition, in future research, a diagnostic test based on the topics in the SHS organic chemistry syllabus could be added to ascertain whether the perceived difficult topics are actually difficult for students to answer questions on. This would help teachers to separate perceived difficulties from the actual difficulties (realities) and be able to address them in their lessons. 


\section{LIMITATIONS OF THIS STUDY}

The students' and teachers' perceptions about organic chemistry and the perceived difficult topics in organic chemistry presented in this paper clearly represent a complex interplay of numerous factors, both systematic and pedagogical. This paper did not attempt to determine best practices in the teaching and learning of organic chemistry but rather provides an overview of the different perceptions about organic chemistry as well as topics that are perceived to be difficult within the organic chemistry learning environment.

\section{REFERENCES}

Adu-Gyamfi, K.R., Ampiah, J.G., \& Appiah, J.Y. (2013). Senior high school chemistry students' performance in IUPAC nomenclature of organic compounds. Cypriot Journal of Educational Sciences, 8(4), 472-483.

Adu-Gyamfi, K.R., Ampiah, J.G., \& Appiah, J.Y. (2017). Students' difficulties in IUPAC naming of organic compounds. Journal of Science and Mathematics Education, 6(2), 77-106.

Anderson, T.L., \& Bodner, G.M. (2008). What can we do about 'Parker'? A case study of a good student who didn't 'get' organic chemistry. Chemistry Education Research and Practice, 9, 93-101.

Ayalew, T.E., \& Ochonogor, C.E. (2015). Assessment of Undergraduate Chemistry Students' Difficulties in Organic Chemistry. ISTE International Conference Proceedings. Unisa Press.

Childs, P.E., \& Sheehan, M. (2009). What's difficult about chemistry? An Irish perspective. Chemistry Education Research and Practice, 10, 204-218.

Davis, G. (2010). Senior Secondary School Students' and Teachers' Perception of the Difficult Organic Chemistry Topics in the Central Region. Available from: https://www.erl.ucc.edu.gh

Domin, D.S., Al-Masum, M., \& Mensah, J. (2008). Students' categorizations of organic compounds. Chemistry Education Research and Practice, 9, 114-121.

Donkoh, S. (2017). What students say about senior high school organic chemistry? International Journal of Environment and Science Education, 12(10), 2139-2152.

Halford, B. (2016). Is there a crisis in organic chemistry education? Teachers say yes but most of the problems aren't new. Chemical and Engineering News, 94(13), 24-25.
Hanson, R. (2014). Using small scale chemistry equipment for the study of some organic chemistry topics-a case study in an undergraduate class in Ghana. Journal of Education and Practice, 5(18), 59-64.

Hanson, R. (2016). Using an embedded conceptual strategy to enhance students' understanding of Le Chatelier's summation of some stress factors on equilibrium position. International Journal for Cross Disciplinary Subjects in Education (IJDSE), 7(3), 2889-2899.

Hanson, R. (2017). Enhancing students' performance in organic chemistry through context-based learning and micro activities-a case study. European Journal of Research and Reflection in Educational Sciences, 5(6), 7-20.

Hassan, A.K., Hill, R.A., \& Reid, N. (2004). Ideas underpinning success in an introductory course in organic chemistry. University Chemistry Education, 8, 40-51.

Jimoh, A.T. (2004). Perception of difficult topics in chemistry curriculum by students in Nigerian secondary schools. Ilorin Journal of Education, $24,71-78$

Johnstone, A.H. (2006). Chemical education research in Glasgow in perspective. Chemistry Education Research and Practice, 7(2), 49-63.

Mupa, P., \& Chinooneka, T.I. (2015). Factors contributing to ineffective teaching and learning in primary schools: Why are schools in decadence? Journal of Education and Practice, 6(19), 125-132.

O'Dwyer, A., \& Childs, P. (2017). Who says organic chemistry is difficult? Exploring perspectives and perceptions. Eurasia Journal of Mathematics, Science and Technology Education, 13(7), 3599-3620.

Ratcliffe, M. (2002). What's difficult about a-level chemistry? Education in Chemistry, 39(3), 76-80.

Taagepera, M., \& Noori, S. (2000). Mapping students' thinking patterns in learning organic chemistry by the use of knowledge space theory. Journal of Chemical Education, 77(9), 1224-1229.

Taber, K. (2002). Chemical misconceptions-prevention, diagnosis and cure. In: Theoretical Background. Vol. 1. Royal Society of Chemistry.

Uchegbu, R.I., Ahuchaogu, A.A., \& Amanze, K.O. (2017). Tertiary institution students' perception of difficult topics in organic chemistry curriculum in Imo state. American Association for Science and Technology (AASCIT) Journal of Education, 3(2), 9-15.

West African Examination Council. (2017). Chief Examiner's Report: General Science Program: May/June West African Senior School Certificate Examination. WAEC.

West African Examination Council. (2018). Chief Examiner's Report: General Science Program: May/June West African Senior School Certificate Examination. WAEC. 


\section{APPENDICES}

\section{Appendix A}

\section{Organic Chemistry Perceptions Questionnaire for Students (OCPQS)}

This questionnaire is an instrument for a study that seeks to find out the perceptions of SHS chemistry students on organic chemistry. There is no right or wrong response.

\section{SECTION A}

BIO DATA

1. Gender (Tick): Male $\square \quad$ Female $\square$

2. AGE (Write in the box):

\section{SECTION B}

\section{General Perception of Organic Chemistry}

Kindly indicate your level of agreement/disagreement with the statements below by ticking under either strongly agree, agree, undecided, disagree or strongly disagree.

\begin{tabular}{|c|c|c|c|c|c|}
\hline Statements & Strongly agree & Agree & Undecided & Disagree & $\begin{array}{l}\text { Strongly } \\
\text { disagree }\end{array}$ \\
\hline \multicolumn{6}{|l|}{$\begin{array}{l}\text { 1. Organic chemistry is a difficult } \\
\text { topic for me }\end{array}$} \\
\hline \multicolumn{6}{|l|}{$\begin{array}{l}\text { 2. Organic Chemistry concepts are } \\
\text { very EU }\end{array}$} \\
\hline \multicolumn{6}{|l|}{$\begin{array}{l}\text { 3.It is easy to solve organic } \\
\text { chemistry problems. }\end{array}$} \\
\hline \multicolumn{6}{|l|}{$\begin{array}{l}\text { 4.I am very happy during organic } \\
\text { chemistry lessons }\end{array}$} \\
\hline \multicolumn{6}{|l|}{$\begin{array}{l}\text { 5.My chemistry teacher's method } \\
\text { of teaching is more attractive } \\
\text { and helped me to understand } \\
\text { organic chemistry concepts well }\end{array}$} \\
\hline \multicolumn{6}{|l|}{ 6. Organic chemistry is interesting } \\
\hline $\begin{array}{l}\text { 7.I enjoy learning organic } \\
\text { chemistry more than the other } \\
\text { aspects of elective chemistry }\end{array}$ & & & & & \\
\hline
\end{tabular}

\section{SECTION C}

\section{Perceptions about Organic Chemistry Topics}

Tick $(\sqrt{ })$ the appropriate column corresponding to your opinion about the topic.

Please be sure to respond to all the items. If you change your mind about your response to an item just cross it out and tick $(\sqrt{ })$ another. You are assured of the confidentiality of your opinion. Thank you. 


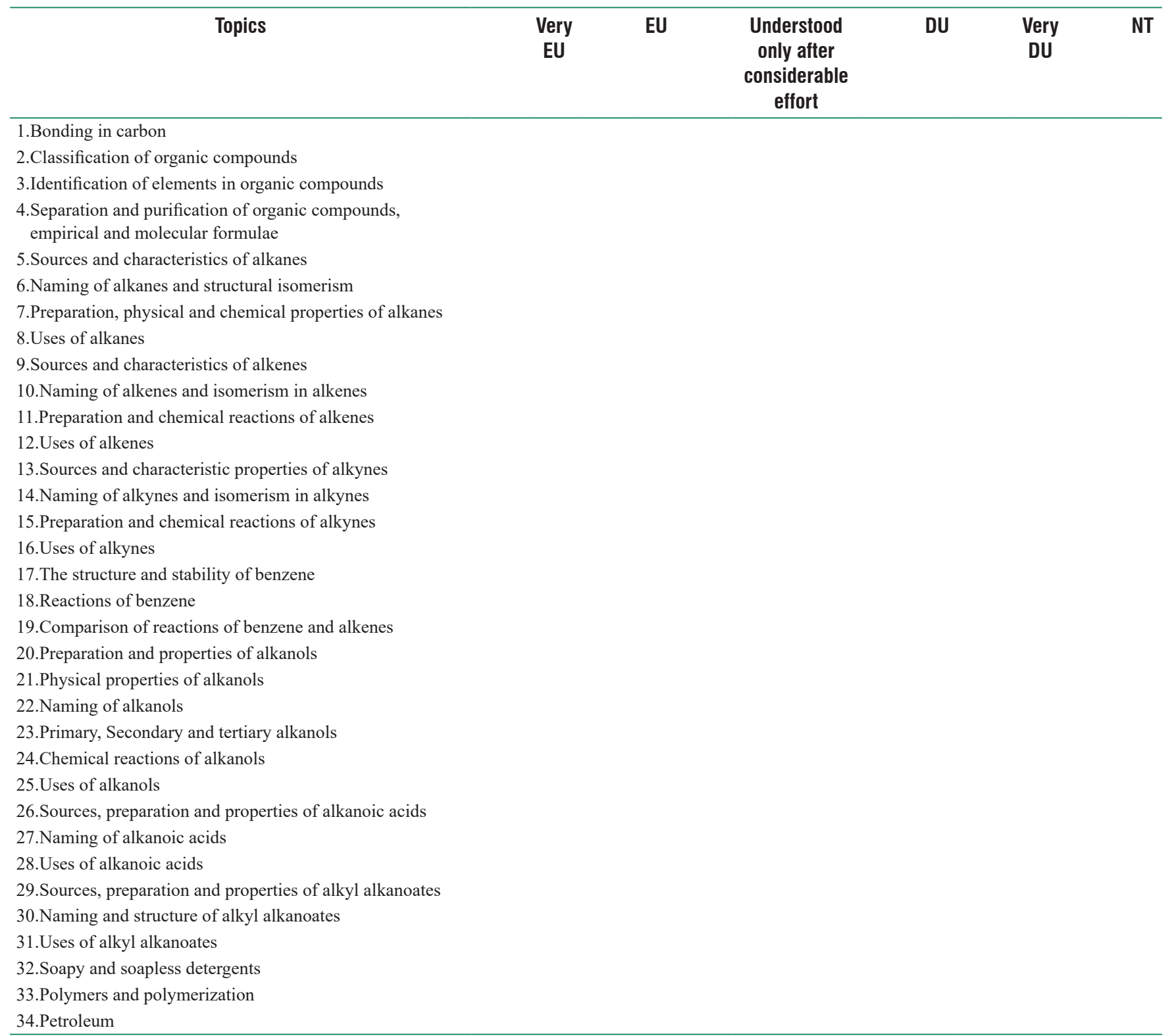

1. Indicate the topic(s) you find most DU in organic chemistry. List three of them, in order of difficulty.

1 .

2 .

3. 


\section{APPENDIX B}

\section{Organic Chemistry Perception Questionnaire for Teachers (OCPQT)}

This questionnaire is an instrument for a study that seeks to find out the perceptions of SHS chemistry teachers on organic chemistry. There is no right or wrong response.

\section{BIODATA}

\section{SECTION A}

1. Gender (Tick): Male

Female

2. Age (Tick): 23-34 years

$$
\begin{aligned}
& 35-44 \text { years } \\
& 45-60 \text { years }
\end{aligned}
$$

3. Academic qualification (tick): Diploma

4. Number of Years in Teaching (Write in the box):

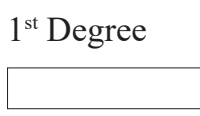

$2^{\text {nd }}$ Degree

Others

\section{SECTION B}

\section{General Perception of Organic Chemistry}

Kindly indicate your level of agreement/disagreement with the statements below by ticking under either strongly agree, agree,

\begin{tabular}{|c|c|c|c|c|c|}
\hline Statements & $\begin{array}{l}\text { Strongly } \\
\text { agree }\end{array}$ & Agree & Undecided & Disagree & $\begin{array}{l}\text { Strongly } \\
\text { disagree }\end{array}$ \\
\hline \multicolumn{6}{|c|}{ 1. Organic chemistry is a difficult topic for me to teach } \\
\hline \multicolumn{6}{|c|}{ 2.Organic Chemistry concepts are very EU } \\
\hline \multicolumn{6}{|c|}{ 3.It is easy to solve organic chemistry problems } \\
\hline \multicolumn{6}{|c|}{$\begin{array}{l}\text { 4.I enjoy teaching organic chemistry topics more than the } \\
\text { other aspects of chemistry }\end{array}$} \\
\hline 5.Organic chemistry topics are not interesting & & & & & \\
\hline
\end{tabular}
undecided, disagree or strongly disagree.

\section{SECTION C}

\section{Perceptions about Organic Chemistry Topics}

Tick $(\sqrt{ })$ the appropriate column corresponding to your opinion about the levels of difficulty of the topics listed below. Please be sure to respond to all the items. If you change your mind about your response to an item just cross it out and tick $(\sqrt{ })$ another. You are assured of the confidentiality of your opinion. Thank you. 


\begin{tabular}{|c|c|c|c|c|c|}
\hline Topics & $\begin{array}{c}\text { Very } \\
\text { easy } \\
\text { to } \\
\text { teach }\end{array}$ & $\begin{array}{l}\text { Easy } \\
\text { to } \\
\text { teach }\end{array}$ & $\begin{array}{l}\text { Not } \\
\text { sure }\end{array}$ & $\begin{array}{l}\text { Difficult } \\
\text { to teach }\end{array}$ & $\begin{array}{c}\text { Very } \\
\text { difficult } \\
\text { to teach }\end{array}$ \\
\hline \multicolumn{6}{|l|}{ 1.Bonding in carbon } \\
\hline \multicolumn{6}{|l|}{ 2.Classification of organic compounds } \\
\hline \multicolumn{6}{|l|}{ 3.Identification of elements in organic compounds } \\
\hline \multicolumn{6}{|l|}{$\begin{array}{l}\text { 4.Separation and purification of organic compounds, } \\
\text { empirical and molecular formulae }\end{array}$} \\
\hline \multicolumn{6}{|l|}{ 5.Sources and characteristics of alkanes } \\
\hline \multicolumn{6}{|l|}{ 6. Naming of alkanes and structural isomerism } \\
\hline \multicolumn{6}{|l|}{ 7.Preparation, physical and chemical properties of alkanes } \\
\hline \multicolumn{6}{|l|}{ 8.Uses of alkanes } \\
\hline \multicolumn{6}{|l|}{ 9. Sources and characteristics of alkenes } \\
\hline \multicolumn{6}{|l|}{ 10. Naming of alkenes and isomerism in alkenes } \\
\hline \multicolumn{6}{|l|}{ 11.Preparation and chemical reactions of alkenes } \\
\hline \multicolumn{6}{|l|}{ 12.Uses of alkenes } \\
\hline \multicolumn{6}{|l|}{ 13. Sources and characteristic properties of alkynes } \\
\hline \multicolumn{6}{|l|}{ 14.Naming of alkynes and isomerism in alkynes } \\
\hline \multicolumn{6}{|l|}{ 15.Preparation and chemical reactions of alkynes } \\
\hline \multicolumn{6}{|l|}{ 16.Uses of alkynes } \\
\hline \multicolumn{6}{|l|}{ 17.The structure and stability of benzene } \\
\hline \multicolumn{6}{|l|}{ 18. Reactions of benzene } \\
\hline \multicolumn{6}{|l|}{ 19. Comparison of reactions of benzene and alkenes } \\
\hline \multicolumn{6}{|l|}{ 20.Preparation and properties of alkanols } \\
\hline \multicolumn{6}{|l|}{ 21.Physical properties of alkanols } \\
\hline \multicolumn{6}{|l|}{ 22.Naming of alkanols } \\
\hline \multicolumn{6}{|l|}{ 23.Primary, Secondary and tertiary alkanols } \\
\hline \multicolumn{6}{|l|}{ 24.Chemical reactions of alkanols } \\
\hline \multicolumn{6}{|l|}{ 25.Uses of alkanols } \\
\hline \multicolumn{6}{|l|}{ 26.Sources, preparation and properties of alkanoic acids } \\
\hline \multicolumn{6}{|l|}{ 27.Naming of alkanoic acids } \\
\hline \multicolumn{6}{|l|}{ 28.Uses of alkanoic acids } \\
\hline \multicolumn{6}{|l|}{ 29.sources, preparation and properties of alkyl alkanoates } \\
\hline 30.Naming and structure of alkyl alkanoates & & & & & \\
\hline 31.Uses of alkyl alkanoates & & & & & \\
\hline 32. Soapy and soapless detergents & & & & & \\
\hline 33.Polymers and polymerization & & & & & \\
\hline 34.Petroleum & & & & & \\
\hline
\end{tabular}

